\title{
Health care providers' perceptions of and attitudes towards induced abortions in sub-Saharan Africa and Southeast Asia: a systematic literature review of qualitative and quantitative data
}

Ulrika Rehnström Loi ${ }^{1 *}$, Kristina Gemzell-Danielsson², Elisabeth Faxelid ${ }^{1}$ and Marie Klingberg-Allvin ${ }^{2,3}$

\begin{abstract}
Background: Unsafe abortions are a serious public health problem and a major human rights issue. In low-income countries, where restrictive abortion laws are common, safe abortion care is not always available to women in need. Health care providers have an important role in the provision of abortion services. However, the shortage of health care providers in low-income countries is critical and exacerbated by the unwillingness of some health care providers to provide abortion services. The aim of this study was to identify, summarise and synthesise available research addressing health care providers' perceptions of and attitudes towards induced abortions in sub-Saharan Africa and Southeast Asia.
\end{abstract}

Methods: A systematic literature search of three databases was conducted in November 2014, as well as a manual search of reference lists. The selection criteria included quantitative and qualitative research studies written in English, regardless of the year of publication, exploring health care providers' perceptions of and attitudes towards induced abortions in sub-Saharan Africa and Southeast Asia. The quality of all articles that met the inclusion criteria was assessed. The studies were critically appraised, and thematic analysis was used to synthesise the data.

Results: Thirty-six studies, published during 1977 and 2014, including data from 15 different countries, met the inclusion criteria. Nine key themes were identified as influencing the health care providers' attitudes towards induced abortions: 1) human rights, 2) gender, 3) religion, 4) access, 5) unpreparedness, 6) quality of life, 7) ambivalence 8) quality of care and 9) stigma and victimisation.

Conclusions: Health care providers in sub-Saharan Africa and Southeast Asia have moral-, social- and gender-based reservations about induced abortion. These reservations influence attitudes towards induced abortions and subsequently affect the relationship between the health care provider and the pregnant woman who wishes to have an abortion. A values clarification exercise among abortion care providers is needed.

Keywords: Induced abortion, Providers' attitudes, Sub-Saharan Africa, Southeast Asia, Systematic review, Thematic analysis

\footnotetext{
* Correspondence: ulrika.rehnstrom@ki.se

'Department of Public Health Sciences/IHCAR, Karolinska Institutet,

Stockholm, Sweden

Full list of author information is available at the end of the article
} 


\section{Background}

Unsafe abortions are directly correlated with poverty, social inequity and the constant, methodical denial of women's' human rights [1]. The United Nations Committee on the Elimination of Discrimination against Women argue that women alone have the right to decide whether to have an abortion [2].

The denial of a pregnant women's right to independently make this decision violates or poses a threat to a number of human rights, including a woman's right to equality, liberty, non-discrimination, privacy, health and to be free from inhumane and degrading treatment, as explicitly articulated by the United Nations [2,3].

Unsafe abortions are a public health burden mainly in low-resource settings, with the highest burden in subSaharan Africa, Latin America and the Caribbean, followed by South and Southeast Asia [4]. At the opposite extreme, the rate of unsafe abortions in Europe and North America is insignificant [4]. A systematic literature review by Khan et al. [5] found that the maternal abortion-associated mortality ratio was 37 deaths per 100.000 live births in subSaharan Africa, 23 per 100.000 in Latin America and the Caribbean and 12 per 100.000 in South Asia. In countries with legal access to safe abortion services, deaths related to abortion are virtually non-existent [5]. According to the most recent global estimates for abortion-related deaths by WHO, unsafe abortions are responsible for approximately 47,000 deaths each year [6]. Kassebaum et al. indicated that abortion-related maternal deaths significantly decreased during 1990 to 2013 at a global level, except for subSaharan Africa where they significantly increased [7].

Induced abortions are legal on various grounds in several sub-Saharan Africa and Southeast Asian countries [8]. However, the health care providers in these countries often persist in viewing induced abortion as immoral, rather than recognising the legal status of abortion in their country [8].

In most high-resource countries, abortion laws were liberalised between 1950 and 1985 on safety and human rights grounds [9]. The most liberal abortion laws permit an abortion at the request of the women. However, there are vast differences in the abortion laws of different countries [10]. The United Nations has identified seven grounds on which an abortion is permitted: (1) to protect life of the mother, (2) to preserve the mother's physical health; (3) to preserve the mother's mental health; (4) in cases of rape or incest; (5) for foetal defects; (6) for socioeconomic reasons and (7) on request [10]. In most countries in sub-Saharan Africa and Southeast Asia, abortion laws are restrictive [10]. An abortion is legal at the request of the women in only two countries in sub-Saharan Africa: Cape Verde and South Africa. Cambodia, Singapore and Vietnam permit an abortion on a broad range of grounds [10]. In the last decade, several nations in these regions have liberalised their abortion laws to reduce the incidence of unsafe abortions. In 2005, Ethiopia approved a liberalised abortion law [11], and Ghana's abortion laws have been fairly liberal since 1985. However, safe, legal abortion has not been well implemented until recent years and unsafe abortions are common in Ghana [12], and complications of induced abortions are the second leading cause of maternal death [13].

Women, particularly adolescent women and those who are poor and/or living in rural areas, often lack information about the legal status of abortions in their country and where to seek safe abortion services. In addition, they may lack the decision-making power and money to seek such services, or they might be discouraged by health care providers' negative attitudes and a lack of confidentiality and privacy [14]. In many societies, abortion is a highly explosive topic, with stigma attached [15]. The latter may prevent women from accessing safe abortion services.

In many low-resource countries, the stigma associated with abortions means that the providers offering these services suffer discrimination in and outside the workplace $[16,17]$. The discrimination causes many providers to cease providing abortion services [16,17]. Furthermore, abortion providers' attitudes may be in conflict with the national abortion law $[18,19]$. These conflicts may cause moral distress and hamper the professionalpatient relationship. The lack of willingness and commitment among health care providers to deliver timely, thoughtful and supportive abortion care may directly or indirectly contribute to maternal mortality due to unsafe abortions. Therefore, it is important to understand health care providers' perceptions of and attitudes towards induced abortions, as they have a substantial effect on the accessibility to abortion services and the quality of these services.

The aim of this systematic literature review was to identify, summarise and synthesise available research addressing health care providers perceptions of and attitudes towards induced abortions in sub-Saharan Africa and Southeast Asia.

\section{Methods}

\section{Study identification}

A comprehensive literature search of three databases (PubMed, CINHAL and Web of Science) and a manual search of reference lists of the identified studies were undertaken. All the searches took place during November 2014 and included all peer-reviewed articles, regardless of the year of publication (1977 - 2014). Each database was searched systematically for relevant citations using a highsensitivity and low-specificity approach, as follows.

The systematic search was segregated into three elements: 1) health care provider, 2) abortion and 3) sub- 
Saharan Africa/Southeast Asia. For each of the elements, a list of relevant medical subject headings $(\mathrm{MeSH})$, free text words, synonyms, abbreviations and alternate spellings that the authors might have used was accumulated. All the MeSH words and free text words were then combined using 'OR' to provide a large range of studies for each element. The three lists for each of the elements were then combined with 'AND' to generate highsensitivity and low-specificity citations that were relevant to all three elements of the research question. The reference lists of the retrieved articles were screened to identify further relevant papers.

\section{Inclusion criteria}

We decided to limit our review to sub-Saharan African and Southeast Asian countries, where the burden of maternal mortality is high. A thorough global analysis of health care providers' attitudes towards abortion in other settings is beyond the scope of this paper and deserves attention in its own right.

The inclusion criteria for this literature review were: all primary quantitative and qualitative research studies that used data collection methods, such as surveys, selfcompleted questionnaires, in-depth interviews, focusgroup discussions and observations to explore health care providers' and students' attitudes towards and perceptions of induced abortion in sub-Saharan Africa and Southeast Asia. The publications had to be written in English and pass a quality check developed by the first author (see Table 1).

\section{Selection of studies}

The first author selected and collected the articles for the review. This procedure included four steps (Figure 1). First, all 1,014 potentially relevant records identified from the electronic searches underwent an initial title and abstract review to determine their relevance according to the inclusion criteria. These records were then imported into bibliographic software EndNote ${ }^{\bullet}$ for reference management. The EndNote ${ }^{\bullet}$ library was later searched to identify duplicate files. All duplicates were deleted, and a single copy of each record was retained. Second, a hard copy of all the potential studies was obtained and analysed according to the inclusion criteria. Studies that did not meet the inclusion criteria were excluded. Third, all articles that met the inclusion criteria were reviewed to determine the quality of the study (see Table 1). Studies that did not meet the pre-set methodological quality criteria, described below, were excluded. This process is clarified under the next section. Finally, the reference lists in the retrieved articles were screened to identify further relevant papers according to the inclusion and quality criteria. Figure 1 describes the reasons for the exclusion of studies.
Table 1 Quality assessment criteria*

\begin{tabular}{ll}
\hline Aims & Criteria \\
Background & $\begin{array}{l}\text { General aims, specific objectives or research } \\
\text { question clearly described. }\end{array}$ \\
Context & $\begin{array}{l}\text { A comprehensive literature review included. } \\
\text { Explanation and justification for the study. }\end{array}$ \\
Sampling/recruitment & $\begin{array}{l}\text { Context of the research adequately described. } \\
\text { Clear description of the sample, including the } \\
\text { size and characteristics of the sample Selection } \\
\text { Study units are representative of the target } \\
\text { population Exclusions and refusals accounted } \\
\text { for and described }\end{array}$
\end{tabular}

Data collection Suitable research design to address the aims of the research. Appropriate data collection instruments are used, piloted, pretested and described Clear description of the research methodology used Researcher - participation relationship adequately considered Ethical issues considered

Data analysis Clear description of the data analysis method, process and findings.

Data interpretation Clear discussion of the research findings. The study presents sufficient original data to support the findings, and to demonstrate that these and the conclusions are grounded in the data Clear integration of the data, interpretation and conclusions Study context and sample considered in the findings

Reliability/validity Reliability and validity of the analysis has been addressed Rigorous data analysis

*Adapted from the Critical Appraisal Skills Programme (CASP) within the Public Health Resource Unit (PHRU) and existing instruments for studies on reproductive health $[18,19]$.

\section{Assessment of the quality of the study and data extraction}

To assess the methodological quality (internal and external validity) of the included studies, the main author developed a checklist of quality criteria based on the critical appraisal skills programme and existing instruments for studies on reproductive health $[19,20]$. The following eight criteria were assessed: 1) aim, 2) background, 3) context, 4) sampling, 5) data collection, 6) data analysis, 7) data interpretation and 8) reliability/validity. Table 1 provides a detailed description of the quality criteria.

Following the initial reading of the 36 included studies; each study was read several times by the main author to appraise the content. Its findings were then summarised on a data extraction form by the main author. The following information was recorded: background of the study, country of research, study population, study characteristics, design and methods, methodological quality, data sampling, data collection, analysis methods and key findings.

\section{Synthesis}

In the review, both qualitative and quantitative data were assessed, and each study was analysed individually. The 


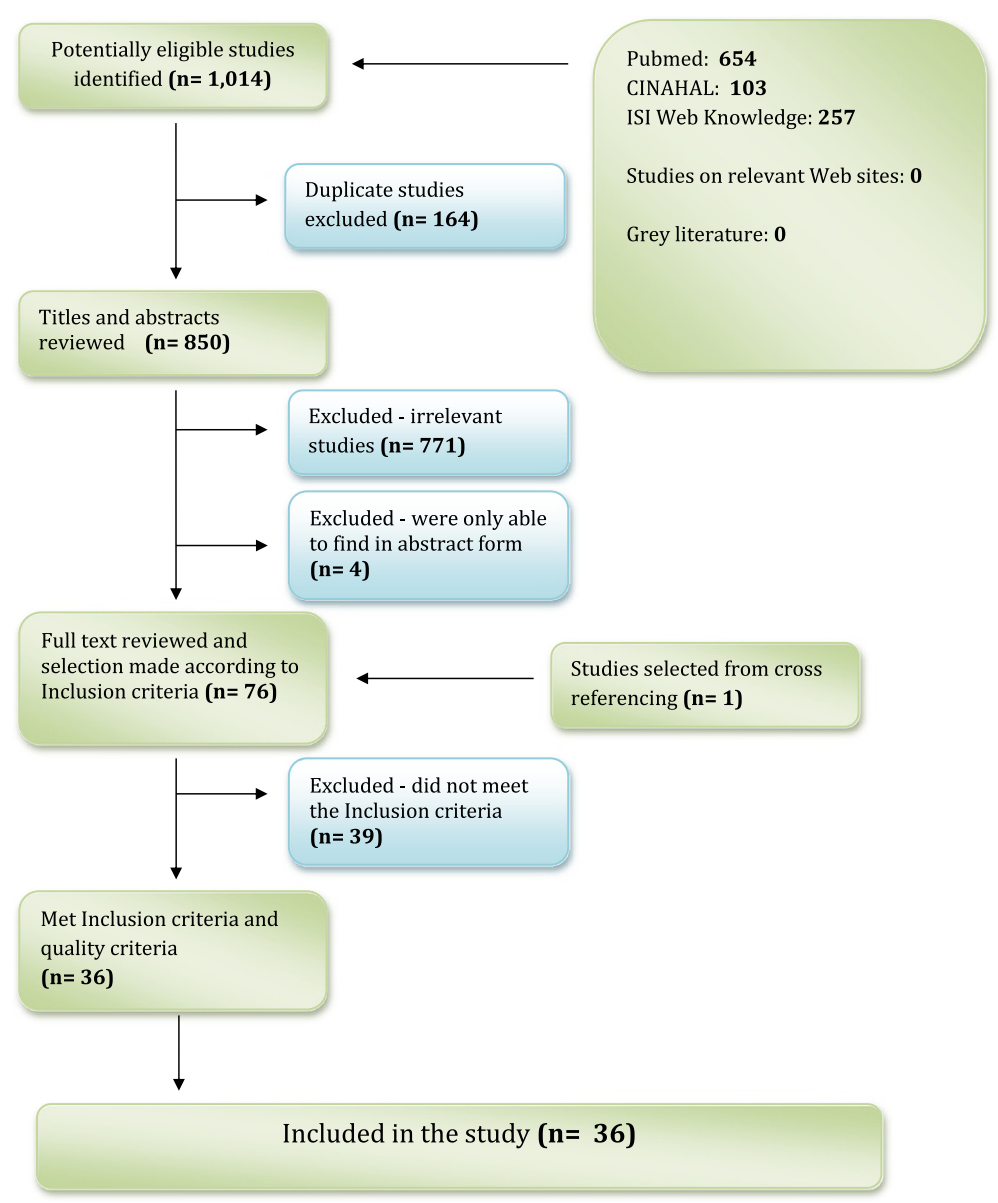

Figure 1 Flow chart for identifying relevant studies.

results from the selected studies were analysed using a thematic analysis that was used previously for synthesising results in systematic literature reviews of qualitative and quantitative studies [20-22]. The 36 studies included in this review were first assessed to categorise key descriptive themes. The key descriptive themes were then systematised in a matrix, and similarities, differences and contradictions were examined. To answer the review question about the attitudes of health care professionals towards induced abortions in sub-Saharan Africa and Southeast Asia, analytical themes were created.

\section{Results}

\section{Description of the studies included in the review}

The 36 studies included in the review were published between 1977 and 2014 and described health care professionals' perceptions of and attitudes towards induced abortions. The studies were conducted in 15 countries: Ethiopia (1), Ghana (5), Indonesia (1), Kenya (1), Mozambique (1), Myanmar (1), Nigeria (4), South Africa (13), Swaziland (1), Thailand (2), Timor Leste (1), Uganda (1), Vietnam (2), Zambia together with Kenya
(1) and Zimbabwe (1). In total, 29 studies were conducted in sub-Saharan Africa, and seven took place in Southeast Asia. Table 2 describes the characteristics of the studies included in the review.

According to the World Bank's analytical income categories [23], the studies were conducted in one upper middle-income country, seven lower middle-income countries and five low-income countries.

Seven of the studies [24-30] used in-depth interviews as the method of data collection, one study used a phenomenological approach to interviews [31], and 19 of the studies used self-completed questionnaires [32-50]. Nine of the studies [16,51-58] had used more than one data collection method, such as surveys, observations, focus group discussions and in-depth-interviews.

The health care providers' attitudes towards induced abortions were classified into nine key descriptive themes: 1) human rights, 2) gender, 3) religion, 4) access, 5) unpreparedness, 6) quality of life, 7) ambivalence, 8) quality of care and 9) stigma and victimisation. These nine key descriptive themes were collapsed into five analytical themes based on their content. 
Table 2 Characteristics of the studies included in the review

Nr. Country Year of publication Study period Abortion law $^{*}$ A

1. Ethiopia $2011 \quad$ March - April 2008 A B DE H+

To answ er the questions: "what does perceptions on safe abortion look like among health care service providers? "What are the factors which affect the perception of health providers towards safe abortion?"

2. Ghan

No information

A B C DE H

To examine in in what ways provider attitudes and values affect the implementation of abortion policy.

3. Timor Leste

2009

$2006-2007$

A

To describe the socio-legal context of unsafe abortion in Timor-Leste

4. South Africa

No Information

$\begin{array}{ll}\text { A B CDEFG } & \text { To investigate health care ethics } \\ \text {-1st H } & \text { regarding Termination of pregnancy }\end{array}$

5. South Africa

6. South Africa

7. Indonesia

No Information

A BCDEFG To assess attitudes of medical students -1 st $H$ to induced abortion

Nov. 2001 - March A B C D E F G To explore attitudes of health care

8. Nigeria

9. Mozambique 2004

10. South Africa

11. South Africa

12. South Africa

2009

13. South Africa

14. Zimbabwe

15. Kenya

1992

16. Vietnam $2002-1$ st H

providers towards medical abortion

Oct. 1990 - April A 1991

No Information $-1 s t+$

to make pregnancy and childbirth safer

To examine the knowledge, attitude and practice of private medical

practitioners on abortion

To document the strengths and deficiencies of abortion care

No Information

$$
\begin{array}{ll}
\text { A BCDEFG } & \text { To explore and describe nurses' } \\
-1 \text { st H } & \text { experiences of being involved }
\end{array}
$$
with abortion care

July-October A BCDEFG To explore health service providers' 2008

$2006-2007$

A BCDEFG - 1st H perceptions of abortion services To explore knowledge, attitudes and
opinions of health care providers' attitude to abortion

No Information A BCDEFG To study attitudes and beliefs about abortion among nurses

No Information $\quad$ A B D E H

To determinate the attitudes of professional health workers to medically supervised abortion

April 1991 A To determine nurses' knowledge and attitudes towards abortion

Sample size/characteristics

431 health providers

Data collection

Reference

A structured, self- $\quad$ ABDI, J. et al. [32]

administered

questionnaire

43 health professionals

In-depth interviews ANITEYE, P. et al. [30]

21 doctors and midwives

In-depth interviews BELTON, S. et al. [24]

1200 registered nurses

Questionnaires and BOTES, A. [16]

Focus-group

discussions

247 medical students

Self-administered BUGA, G.A. [33]

questionnaire

20 public health nurses and In-depth interviews COOPER, D., et al. [25] doctors

28 Physicians, 16

In-depth interviews DJOHAN, E., et al. [26]

Midwives, 16 TBA 16 PLKB

Total: 76

48 private practitioners

Structured

questionnaire

ETUK, S.J. et al. [34]

99 Midwives and nurses

Questionnaire

GALLO, M.F., et al. [35]

Nurses

Phenomenological GMEINER, A.C., et al. [31] interviews

19 providers and hospital managers

34 health care providers

24 male and 114 female nurses In total 138

In-depth interviews HARRIES, J. et al. [27]

In-depth interviews HARRIES, J. et al. [53] and one focus group discussion

Self administered HARRISON, A., et al. [36] questionnaire

196 doctors, 1053 nurses In Self administered KASULE, J., et al. [37] total 1249

anonymous

questionnaire

218 nurses

Self-administered KIDULA, N. A., et al. [38] questionnaire 
Table 2 Characteristics of the studies included in the review (Continued)

\begin{tabular}{|c|c|c|c|c|c|c|c|}
\hline & & & & $\begin{array}{l}\text { To explore the midwives' perspectives } \\
\text { on adolescent sexuality and abortion, } \\
\text { and what they consider to be quality } \\
\text { abortion care }\end{array}$ & $\begin{array}{l}40 \text { Midwives; } 28 \text { doctors In } \\
\text { total } 68\end{array}$ & $\begin{array}{l}\text { Observations and } \\
\text { focus-group dis- } \\
\text { cussions (FGD) }\end{array}$ & $\begin{array}{l}\text { KLINGBERG-ALLVIN, M., } \\
\text { et al. [54] }\end{array}$ \\
\hline 17. Vietnam & 2007 & 2003 & $\begin{array}{l}A B C D E F G \\
H\end{array}$ & $\begin{array}{l}\text { To investigate midwifery students' } \\
\text { values and attitudes towards adolescent } \\
\text { sexuality, abortion and contraception }\end{array}$ & 235 midwifery students & $\begin{array}{l}\text { Quantitative survey } \\
\text { complemented } \\
\text { with } 18 \text { qualitative } \\
\text { interviews }\end{array}$ & $\begin{array}{l}\text { KLINGBERG-ALLVIN, M., } \\
\text { et al. [55] }\end{array}$ \\
\hline 18. South Africa & 2005 & No Information & $\begin{array}{l}\text { A BCDEFG } \\
-1 \text { st H }\end{array}$ & $\begin{array}{l}\text { To explore the lived experience of } \\
\text { midwives who assist with TOP }\end{array}$ & 3 nurses & In-depth interviews & MAYERS, P.M. et al. [28] \\
\hline 19. Swaziland & 2008 & $\begin{array}{l}\text { January - March } \\
2005\end{array}$ & $A B C D E H$ & $\begin{array}{l}\text { To explore health workers' perceptions } \\
\text { of adolescent SRH services in Swaziland }\end{array}$ & 56 midwives & $\begin{array}{l}\text { Self-administered } \\
\text { questionnaire }\end{array}$ & MNGADI, P. T., et al. [39] \\
\hline 20. South Africa & 2008 & No information & $\begin{array}{l}\text { A B C D E F G } \\
1^{\text {s t } H}\end{array}$ & $\begin{array}{l}\text { To investigate professional nurses' attitudes } \\
\text { towards abortion care }\end{array}$ & 25 nurses & Questionnaire & MOKGETHI, N. E. et al. [40] \\
\hline 21. Ghana & 2007 & August 2003 & $A B C D E H$ & $\begin{array}{l}\text { To assess physician's knowledge and } \\
\text { attitude towards abortion }\end{array}$ & 74 physicians & $\begin{array}{l}\text { Self-administered } \\
\text { questionnaire }\end{array}$ & MORHE, E.S. et al. [41] \\
\hline 22. Nigeria & 2005 & No information & A & $\begin{array}{l}\text { To investigate the attitudes and practices } \\
\text { of physicians towards abortion }\end{array}$ & 232 private practitioners & $\begin{array}{l}\text { Structured } \\
\text { questionnaire }\end{array}$ & OKONOFUA, F. E. et al. [42] \\
\hline 23. Nigeria & 2011 & No information & A & $\begin{array}{l}\text { To assess the attitudes of staff at } \\
\text { reproductive health services }\end{array}$ & 136 senior practitioners & Questionnaire & $\begin{array}{l}\text { OMO-AGHOJA, L.O. } \\
\text { et al. [43] }\end{array}$ \\
\hline 24. Nigeria & 2009 & $\begin{array}{l}27 \text { December } \\
2005 \text { to } 25 \text { March } \\
2006\end{array}$ & A & $\begin{array}{l}\text { To understand PAC services provided } \\
\text { by private medical practitioners }\end{array}$ & $\begin{array}{l}96 \text { private medical } \\
\text { practitioners }\end{array}$ & Questionnaire & ONAH, H. E. et al. [44] \\
\hline 25. Uganda & 2014 & $\begin{array}{l}\text { February - March } \\
2012\end{array}$ & A & $\begin{array}{l}\text { To explore physicians' and midwives' } \\
\text { perceptions of PAC }\end{array}$ & $\begin{array}{l}10 \text { Doctors and } 17 \text { Midwives } \\
\text { In total } 27\end{array}$ & In-depth Interviews & PAUL, M., et al. [29] \\
\hline 26. Ghana & 2013 & Fall 2009 & $A B C D E H$ & $\begin{array}{l}\text { To explore the reasons women continue } \\
\text { to die from unsafe abortion }\end{array}$ & 4 Physicians & $\begin{array}{l}\text { Open ended } \\
\text { interviews and } \\
\text { Focus-group } \\
\text { discussion }\end{array}$ & PAYNE, M.C., et al. [51] \\
\hline 27. Thailand & 1986 & $1980-1981$ & $A B C D E$ & $\begin{array}{l}\text { To demonstrate health professionals' } \\
\text { attitudes toward abortion }\end{array}$ & $\begin{array}{l}625 \text { Doctors, Nurses and } \\
\text { social workers }\end{array}$ & $\begin{array}{l}\text { Self-administered } \\
\text { questionnaire }\end{array}$ & PHUAPRADIT, W., et al. [45] \\
\hline 28. South Africa & 1998 & No information & $\begin{array}{l}\text { A BCDEFG } \\
-1 \text { st H }\end{array}$ & $\begin{array}{l}\text { To explore and describe nurses' } \\
\text { experience of abortion }\end{array}$ & 1200 nurses & $\begin{array}{l}\text { Focus-group } \\
\text { discussions, } \\
\text { interviews and } \\
\text { observations }\end{array}$ & $\begin{array}{l}\text { POGGENPOEL, M., } \\
\text { et al. [56] }\end{array}$ \\
\hline 29. South Africa & 2004 & No information & $\begin{array}{l}\text { A BCDEFG } \\
-1 \text { st H }\end{array}$ & $\begin{array}{l}\text { To compile a profile of the characteristics } \\
\text { and/or beliefs held by nurses who choose } \\
\text { to become abortion providers }\end{array}$ & 22 nurses & $\begin{array}{l}\text { Focus-group } \\
\text { discussion and } \\
\text { deep-interviews }\end{array}$ & POTGIETER, C [57] \\
\hline 30. Ghana & 2013 & March - April 2008 & $A B C D E H$ & $\begin{array}{l}\text { To understand pathways to induced } \\
\text { abortion in Ghana and the role health } \\
\text { care providers play }\end{array}$ & $\begin{array}{l}11 \text { Family planning nurses } \\
\text { and } 8 \text { obstetricians/ } \\
\text { gynaecologists In total } 19\end{array}$ & $\begin{array}{l}\text { Focus-group } \\
\text { discussion and in- } \\
\text { depth interviews }\end{array}$ & $\begin{array}{l}\text { SCHWANDT, H.M., } \\
\text { et al. [51] }\end{array}$ \\
\hline 31. Myanmar & 2012 & March - May 2011 & A & To find out medical students' knowledge & 1,060 Medical students & Questionnaire & TEY, N.P., et al. [50] \\
\hline
\end{tabular}


Table 2 Characteristics of the studies included in the review (Continued)

\begin{tabular}{|c|c|c|c|c|c|c|c|c|}
\hline 32. & Thailand & 1977 & No information & $A B C D E$ & $\begin{array}{l}\text { To evaluate the attitudes of medical } \\
\text { students towards abortion }\end{array}$ & 318 medical students & Questionnaires & VARAKAMIN, S. et al. [46] \\
\hline 33. & Ghana & 2010 & February 2007 & $A B C D E H$ & $\begin{array}{l}\text { To assess the capacity and willingness } \\
\text { of midwifery tutors to teach abortion } \\
\text { care }\end{array}$ & 74 Midwifery tutors & $\begin{array}{l}\text { Structured } \\
\text { questionnaire }\end{array}$ & VOETAGBE, G. et al. [47] \\
\hline 34. & South Africa & 1995 & No information & $\begin{array}{l}\text { A BCDEFG } \\
-1 \text { st H }\end{array}$ & $\begin{array}{l}\text { To explore the understandings and } \\
\text { responses of nurses towards abortion }\end{array}$ & $\begin{array}{l}35 \text { Primary Health Care } \\
\text { Nurses }\end{array}$ & $\begin{array}{l}\text { Observations and } \\
\text { interviews }\end{array}$ & WALKER, L. [58] \\
\hline 35. & $\begin{array}{l}\text { Kenya and } \\
\text { Zambia }\end{array}$ & 2006 & Sept. - Dec. 2001 & $\begin{array}{l}\text { Kenya A } \\
\text { Zambia A B C } \\
\text { E F }\end{array}$ & $\begin{array}{l}\text { To investigate attitudes among Kenyan } \\
\text { and Zambian nurse-midwives toward } \\
\text { adolescent SRH problems, in order to } \\
\text { improve services for adolescents. }\end{array}$ & $\begin{array}{l}322 \text { Nurses from Kenya } 385 \\
\text { Nurses from Zambia In total } \\
707 \text { Nurses }\end{array}$ & Questionnaires & WARENIUS, L. U., et al. [48] \\
\hline 36. & South Africa & 2012 & $2005-2007$ & $\begin{array}{l}\text { A BCDEFG } \\
-1 \text { st H }\end{array}$ & $\begin{array}{l}\text { To assess attitudes about abortion } \\
\text { provision and future practice intentions } \\
\text { of medical students }\end{array}$ & 1308 medical students & $\begin{array}{l}\text { Self-administered } \\
\text { questionnaire }\end{array}$ & WHEELER, S.B. et al. [49] \\
\hline
\end{tabular}

$A=$ To protect woman's life $D=$ Rape $G=$ On request 1st - First trimester only.

$B=$ Physical health $E=$ Foetal defects $\mathrm{H}=$ Incest.

$\mathrm{C}=$ Mental health $\mathrm{F}=$ Socio-economic factors.

$+=$ Abortion permitted on additional enumerated grounds relating to such factors as the woman's age or capacity to care for a child.

*Source: CENTER FOR REPRODUCTIVE RIGHTS (2009) World Abortion Laws 2009 Fact Sheet.

http://reproductiverights.org/sites/crr.civicactions.net/files/documents/pub_fac_abortionlaws2009_WEB.pdf. 


\section{Human rights and quality of life}

The synthesis revealed that health care providers, in general, were uncertain about the legal status of abortion in their countries [24-26,32,37,41,43,47,53]. Some health care providers considered induced abortion as a significant public health problem and perceived the legalisation of abortion as a positive step because, otherwise, women would opt for an unsafe abortion, risking their lives $[26,29-32,37,47,49,57]$. However, nurses and midwives from South Africa, which has a more liberal abortion law, concluded that if women had the right to make choices regarding the termination of their pregnancy, health personnel should have the right to choose whether to work in abortion clinics $[27,36,53,56]$.

The health care personnel who participated in the studies conducted in South Africa and Vietnam considered that an increase in urbanisation and improvements in access to education had changed the context of sexual and reproductive behaviour [27,36,53,54]. As a result, they believed that women and adolescents were in need of sexual and reproductive health information, including family planning, to prevent unwanted pregnancies and induced abortions [27,36,53,54].

According to the results, the majority of health care providers were supportive of abortions in cases where the pregnancy was due to rape or incest, severe genetic disorders were present, or it was necessary to save the life of the woman $[24,26-30,35,36,38,40,45,46,49,53]$. Only one study included in this literature review explored nurses' attitudes towards abortions among women living with HIV/AIDS [40]. In this South African study, the respondents suggested that these women should have access to abortion services.

Regardless of the liberal abortion laws in South Africa, the nurses and midwives stated that the foetus should also have rights $[16,36,40]$. They asserted that national hospitals were established to save lives, not to eliminate them $[16,36,40]$. In addition, the nurses disapproved of childless women having an abortion $[16,36,40]$.

A South African study revealed that nurses who had been trained in abortion care considered a woman's access to an induced abortion as a human right [57]. They felt that their training would enable them to reduce the maternal mortality and morbidity caused by unsafe abortions [57]. A recent study among medical students in South Africa found that 70 per cent of the respondents believed that it is the right of the woman to decide whether to have an abortion [49]. In one study from Ghana, it was found that human rights arguments were used both for and against abortion care [30].

\section{Gender, stigma and victimisation}

In three of the studies, the nurses and midwives stated that women should give birth and care for their children and expressed the view that induced abortion was 'terminating motherhood' [17,26,28]. In the same studies, these nurses and midwives considered that women who choose an abortion denied their role as mothers and thus rejected their identity as women.

Three studies conducted in Southeast Asia (Indonesia and Thailand) reported differences between the sexes regarding attitudes towards induced abortion, with female health care providers apparently having more conservative attitudes than male personnel $[26,45,46]$. Only one study from Thailand reported differences in attitudes towards abortion in relation to the respondent's age [45]. This study suggested that the attitudes of younger nurses towards abortions were more liberal than those of older nurses.

In several studies, abortion providers mentioned they were perceived by their colleagues as murderers or 'baby killers' $[16,25,28,33,36,40,54,56-58]$. In two studies from South Africa, the providers considered that an abortion was a threat to the community, an act of disgrace and a waste of taxpayers' money [16,58].

However, some nurses from South Africa indicated that they would assist a woman who suffered complications following an unsafe abortion. They considered that the stigma associated with the induced abortion would be attached to the individual who performed the abortion procedure, rather than the nurse who was only fulfilling her professional duty in saving a woman's life $[36,56]$. At the same time, they verbalised that they had chosen nursing because they wanted to preserve life and promote health, not act as murderers [36,56]. Gynaecologists and general practitioners participating in an Indonesian study articulated that the life of a foetus commences after 120 days of pregnancy [26]. Therefore, they did not consider 'menstrual regulation' as a form of abortion, and it was thus widely accepted [26].

In both sub-Saharan Africa and Southeast Asia, the health care providers experienced personal conflicts, stigmatisation and victimisation because of the negative attitudes of family, community, fellow health care workers and policymakers $[18,26,28-30,40,51,52]$. Colleagues and friends rejected them and voiced negative comments, for example, calling them 'killers' [16,25,27,28,40].

Moreover, the synthesis emphasised that nurses in Southeast Asia and South Africa strongly disapproved of pre-marital sex, although this was described as a modern trend among the young and unmarried [26,36,39,52,54,55]. Nevertheless, pregnancy outside of marriage was not accepted $[26,36,39,54,55]$. Nurses in Vietnam considered that not having pre-marital sex was the best solution to reduce abortion rates among unmarried young women $[54,55]$.

\section{Religion}

Eighteen studies from sub-Saharan Africa and Southeast Asia identified religion as the most important factor 
influencing the attitudes of health care providers towards induced abortions. [16,24,26,28,30-34,36,37,40,43, $44,47,56-58]$. The respondents in those studies believed that only God can decide between life and death and that abortion was a sin. However, in a recent study from South Africa, the nurses viewed abortions differently, depending on whether they were medical or surgical [25]. They perceived that a medical abortion was in the hands of the woman and therefore the woman, not the nurse, had to answer to God for her actions [25].

\section{Unpreparedness and ambivalence}

In the majority of the studies, the health care providers and students revealed that they felt unqualified and unprepared for work in the area of induced abortions $[26,28,29,31,34-41,44,45,47,48,50,53-58]$. In addition, they reported a lack of standard care guidelines and support and highlighted the need for cognitive, emotional and spiritual support [26,28,31,34-41,44,45,47,48,53-58].

Nurses from South Africa considered abortion to be against the nurses' professional code, which requires them to save lives [36]. The nurses expressed ambivalence between their professional responsibilities and personal norms and values. They were angry with the patients who requested induced abortions, blaming them for destroying the nurse's pledge to be a caregiver $[16,28,36,56]$.

\section{Access and quality of care}

In general, the nurses and midwives disliked being involved with abortion services, and they commonly reported hesitance in providing these services $[16,28,38$, $40,48,53,55,56,58]$. Midwifery students from Vietnam revealed that the main reason for choosing midwifery as a profession was to care for women in labour and delivery, and hardly any of the students wanted to work in the area of abortion services [55]. Similar attitudes were reported among physicians [53]. Furthermore, managers in two studies from South Africa expressed difficulties when recruiting, retaining and scheduling health care providers for induced abortion procedures $[28,53]$. Three other studies from South Africa concluded that nurses' resistance to providing abortion services was a powerful barrier against access safe abortion services, with nurses' and midwives' strong opposition to abortion affecting rural women in particular $[16,25,36]$.

Several studies from sub-Saharan Africa showed that nurses and midwives have judgmental attitudes towards abortion patients $[31,36,40,58]$. In general, the nurses seemed to withdraw from the patients and ignored their responsibilities as caregivers $[16,31,39,40,54]$. Furthermore, respondents from both sub-Saharan Africa and Southeast Asia said they could not provide holistic nursing care to women undergoing an induced abortion because they had negative feelings about the woman's decision [36,55]. The nurses and midwives also recognised that these women received inadequate care due to the poor relationship between the nurse and the patient $[28,39,40,55,56]$.

On the other hand, a study by Cooper et al. [25] gave a positive view on nurses' and midwives' attitudes towards abortion. In this study, the nurses expressed a strong interest in medical abortions. In other studies, health care providers, in general, preferred medical abortions, as these required minimal involvement on their part in the abortion process [25,27]. Furthermore, early termination of pregnancy (i.e. menstrual regulation) was more accepted among health care providers than second-trimester abortions $[26,27,46]$.

\section{Discussion}

\section{Main findings}

In total, 36 studies with qualitative or quantitative data from 15 different countries met the inclusion criteria. A thematic analysis of the data indicated that health care providers in sub-Saharan Africa and Southeast Asia have negative feelings about induced abortions.

\section{Strengths}

To our knowledge, this is the first systematic review to evaluate health care providers' perceptions of and attitudes towards induced abortions in sub-Saharan Africa and Southeast Asia. The data are based on the individual participant's perspective of induced abortions.

\section{Limitations}

It is critical to note that the review is limited to 15 countries: 10 in sub-Saharan Africa and five in Southeast Asia. Although the key themes were common across most of the studies, we do not suggest that health care providers' perceptions of and attitudes towards induced abortions will be homogenous in all countries in subSaharan Africa and Southeast Asia. Non of the studies that we reviewed measured the effect of health care providers' perceptions of and attitudes towards induced abortions on access to safe, high-quality abortion care.

Further limitations of the review include the following: 1) 36 percent of the studies were from South Africa, making it difficult to generalise the findings to other populations or settings; 2) only one article reported provider attitudes in Ethiopia, which is the second largest country in sub-Saharan Africa and the abortion law was liberalized almost ten years ago and legal, induced abortion services have rolled out nationwide since then. Provider attitudes might be more positive toward abortion and abortion care in Ethiopia than in other countries in the region. 3) The method of data collection was different in each study, and the research question varied between the studies; 4) none of the studies used questions/ 
statements in a Likert format when assessing the perceptions' of or attitudes towards induced abortions, and they were thus not able to capture the intensity of the providers' feelings about induced abortions, 5) most of the studies asked for provider's opinions on induced abortions rather than directly measuring practice, 6) many studies did not consider other influencing factors, such as sex, age and further education or training, 7) the sample selection of the respondents differed according to the study, and 8) the articles were published during a long period (1977-2014), and attitudes towards abortions might have changed in the two regions during this time. Thus, caution is needed with regard to generalisation of the results.

\section{Interpretations}

This systematic literature review demonstrated that health care providers in sub-Saharan Africa and Southeast Asia have conservative attitudes towards induced abortions. These attitudes were manifested in a judgmental approach towards women with unwanted pregnancies who requested an induced abortion. The health care providers described how these women were ignored and treated with a lack of respect.

In general, the participants viewed an induced abortion as ending a human life and considered it a mortal sin. Religious beliefs affected these views. However, many providers considered that menstrual regulation was acceptable and did not view it as an abortion. Likewise, nurses in South Africa perceived medical abortion as different from surgical abortion, with the former widely accepted as being in the hands of the women who had to answer to God for their actions, not the nurse. In cases where the pregnancy was due to rape or incest, the health care providers seemed to have more sympathy for the woman, and they did not blame the abortion on her not using contraceptives.

One important finding of this review was that some of the nurses and midwives considered that the expectation to provide an induced abortion conflicted with their professional duty to protect life, based on the Code of Ethics for Nurses. Many of the nurses cited this code and highlighted how it contradicted the provision of abortion care services and thus created feelings of guilt, ambivalence and anxiety among nurses.

Midwives mentioned that they were trained to assist women in labour and delivery, not to assist during the termination of a pregnancy. Both the "Essential Competencies for Basic Midwifery Practices 2010" and the new ICM model for the midwifery curriculum by the International Confederation of Midwives include abortion care and family planning services [59,60]. However, a striking finding in this review was that the nurses and midwives seemed to be unprepared to care for women with unwanted pregnancies.

The World Health Organization recommends task shifting, which is a practice of delegation, whereby certain tasks are distributed from physicians to nurses and midwives [61]. In task shifting, the heath care workforce is used in a more efficient way, as the roles of health care workers are optimised [61]. Studies conducted in South Africa, Vietnam and Nepal showed that the provision of abortion care by midlevel health care providers is as safe and effective as the abortion care provided by physicians $[62,63]$. However, task shifting might be challenging to implement if nurses and midwives are reluctant to provide abortion care. This review emphasises that health care providers, in general, and nurses and midwives, in particular, need values clarification and technical training in comprehensive abortion care before they can commit to the responsibility of providing quality abortion care.

Access to safe, legal induced abortion, postabortion care (which occurs after an unsafe abortion) and family planning is fundamental to reduce maternal mortality and morbidity related to unsafe abortions $[64,65]$. The conservative attitudes towards induced abortions among health care providers in sub-Saharan Africa and Southeast Asia might also affect access to post-abortion care and, consequently, post-abortion contraceptive counselling.

It is essential to highlight that the majority of the studies included in this review were conducted in South Africa, where it is known that many health care providers are conscientious objectors to the provision of safe abortions $[17,66]$. The refusal to assist in abortion services is frequently based on moral, religious, ethical or philosophical beliefs. As reported elsewhere, such conscientious objections to abortion provision are an abuse of women's rights and potentially harmful to women's health [67]. A recent study from Ghana indicates that a favourable attitude toward abortion among health care providers' is not associated with safe abortion provision. On the other hand, it was noticed that the odds of providing safe abortions lowers by 57 percent when the health care provider is Catholic in comparison to other religions. Furthermore, the same study found that providers' confidence in their capability to offer safe abortion is fundamental [68].

Abortion care providers need to be prepared, supported and assisted $[67,68]$. The ethical dilemmas of reproductive health care providers charged with providing abortion services require more attention in pre-service and in-service training programmes. The pre-graduation curricula for health care providers in sub-Saharan Africa and Southeast Asia should include training in comprehensive abortion care, such as technical skills, interpersonal skills, value clarification, and communication and 
counselling in family planning and abortion [69]. Some researchers have argued that value clarification, together with supportive follow-up, may have a positive impact on health care workers' attitudes [70,71].

The impact of health care providers' attitudes on access to abortion care and the availability of quality abortion care, in addition to what extent value clarification can positively influence these attitudes, remains to be studied. Finally, strategies to decrease barriers to midwifery-led induced abortion and post-abortion care need to be evaluated to expand access to abortion care.

The findings of this review can be used to design interventions to increase women's access to safe abortion care, post-abortion care and family planning services in specific regions.

\section{Conclusions}

This systematic literature review suggests that religious convictions, beliefs about professional roles and ethics and feelings of unpreparedness frequently give rise to dilemmas among health care providers responsible for the provision of abortion care in sub-Saharan Africa and Southeast Asia. Moral-, social- and gender-based reservations about induced abortions appear to influence health care providers' perceptions of and attitudes towards induced abortions and, consequently, their relationship with the patient who wants an abortion. Political commitments and resources are needed to ensure that health care providers are trained to develop the competencies to enable them to perform safe, highquality abortions and to advocate for abortion care.

Furthermore, this review found that health care providers considered menstrual regulation and medical abortion more acceptable than manual vacuum aspiration. Hence, stakeholders and policy planners urgently need to introduce these two abortion methods, especially in rural health districts, to improve access to abortion services and, consequently, reduce maternal morbidity and mortality due to unsafe abortions. The findings from this review have implications for policy makers and hospital managers when organising health care services. Introducing value clarification and training in abortion care and services might increase the availability and accessibility of quality abortion care.

\section{Details of ethical approval}

Ethical approval was not necessary because the literature review used secondary data from published articles.

\section{Competing interests}

The authors declare that they have no competing interests.

\section{Authors' contributions}

MKA visualised the systematic literature review and, together with EF and $K G D$, secured funding for the same. URL conducted the literature search, reviewed the identified studies, extracted the data and synthesised the findings for the analysis. URL wrote the first draft of the article. All the authors edited the manuscript and approved the final version.

\section{Acknowledgements}

The authors thank Amanda Cleeve for assisting in the proofreading of the manuscript.

\section{Funding}

Vetenskapsrådet, Sweden funded this project.

\section{Author details}

'Department of Public Health Sciences/IHCAR, Karolinska Institutet, Stockholm, Sweden. 'Department of Women's and Children's Health, Karolinska Institutet/Karolinska University Hospital Stockholm, Stockholm, Sweden. ${ }^{3}$ School of Education, Health and Social studies, Dalarna University, Falun, Sweden.

Received: 20 May 2013 Accepted: 3 February 2015

Published online: 12 February 2015

\section{References}

1. Gasman N, Blandon MM, Crane BB. Abortion, social inequity, and women's health: obstetrician-gynecologists as agents of change. Int J Gynaecol Obstet. 2006;94(3):310-6.

2. United Nations Committee on the Elimination of Discrimination against Women: General Recommendation 24: Article 12 of the Convention (women and health) (20th Sess., 1999), [http://www.un.org/womenwatch/ daw/cedaw/recommendations/recomm.htm\#recom24]

3. Zampas C, Gher JM. Abortion as a human right-international and regional standards. Human Rights Law Rev. 2008:8(2):249-94.

4. Grimes DA, Benson J, Singh S, Romero M, Ganatra B, Okonofua FE, et al. Unsafe abortion: the preventable pandemic. Lancet. 2006;368:1908-19.

5. Khan KS, Wojdyla D, Say L, Gulmezoglu AM, Van Look PF. WHO analysis of causes of maternal death: a systematic review. Lancet. 2006;367(9516):1066-74.

6. World Health Organization. Unsafe Abortion: Global and Regional Estimates of the Incidence of Unsafe Abortion and Associated Mortality in 2008. 6th ed. Geneva, Switzerland: World Health Organization; 2011.

7. Kassebaum N, Bertozzi-Villa A, Coggeshall MS, Shackelford KA, Steiner C, Heuton KR, et al. Global, regional, and national levels and causes of maternal mortality during 1990-2013: a systematic analysis for the global burden of disease study 2013. Lancet. 2014;384(9947):956.

8. Sedgh G, Rossier C, Kabore I, Bankole A, Mikulich M. Induced abortion: estimated rates and trends worldwide. Lancet. 2007;370(9595):1338-45.

9. Rahman A, Katzive L, Henshaw SK. A global review of laws on induced abortion, 1985-1997. Int Fam Plann Persp. 1998;24(2):56-64.

10. United Nations: World abortion policies 2011, [http://www.un.org/esa/ population/publications/2011abortion/2011wallchart.pdf]

11. Gebreselassie H, Fetters $T$, Singh $S$, Abdella A, Gebrehiwot $Y$, Tesfaye $S$, et al. Caring for women with abortion complications in Ethiopia: national estimates and future implications. Int Perspect Sex Reprod Health. 2010;36(1):6-15.

12. Sundaram A, Juares F, Bankole A, Singh S. Factors associated with abortion-seeking and obtaining a safe abortion in Ghana. Stud Fam Plann. 2012:43(4):273-86.

13. Ghana Statistical Service (GSS), GHSG, and Macro International. Ghana Maternal Health Survey 2007. Calverton (MD): GSS, GHS, and Macro International; 2009.

14. World Health Organization. The World Health Report 2005, Make Every Mother and Child Count. Geneva, Switzerland: World Health Organization; 2005.

15. Norris A, Bessett D, Steinberg JR, Kavanaugh ML, De Zordo S, Becker D. Abortion stigma: a reconceptualization of constituents, causes, and consequences. Womens Health Issues. 2011;21(3 Suppl):S49-54.

16. Botes $A$. Critical thinking by nurses on ethical issues like the termination of pregnancies. Curationis. 2000;23(3):26-31.

17. Harries J, Cooper D, Stebel A, Colvin CJ. Conscientious objection and its impact on abortion service provision in South Africa: a qualitative study. BMC Reprod Health. 2014;11(1):16.

18. Hill A, Spittlehouse C. What is critical appraisal? Evidence Based Med 2003;3(2):1-8.

19. World Health Organization. Social Science Methods for Research on Reproductive Health. Geneva, Switzerland: World Health Organization; 1999. 
20. Nagata JM, Hernandez Ramos I, Sivasankara Kurup A, Albrecht D, Vivas Torrealba C, Franco PC. Social determinants of health and seasonal influenza vaccination in adults $>=65$ years: a systematic review of qualitative and quantitative data. BMC Public Health. 2013;13(1):388.

21. Clarke G, Harrison K, Holland A, Kuhn I, Barclay S. How are treatment decisions made about artificial nutrition for individuals at risk of lacking capacity? a systematic literature review. PLoS One. 2013;8(4):e61475.

22. Thomas J, Harden A. Methods for the thematic synthesis of qualitative research in systematic reviews. BMC Med Res Methodol. 2008;8:45.

23. World Bank Country Classifications. [http://data.worldbank.org/about/ country-classifications/country-and-lendinggroups]

24. Belton S, Whittaker A, Fonseca Z, Wells-Brown T, Pais P. Attitudes towards the legal context of unsafe abortion in Timor-Leste. Reprod Health Matt. 2009;17(34):55-64.

25. Cooper D, Dickson K, Blanchard K, Cullingworth L, Mavimbela N, von Mollendorf $C$, et al. Medical abortion: the possibilities for introduction in the public sector in South Africa. Reprod Health Matt. 2005;13(26):35-43.

26. Djohan $\mathrm{E}$, Indrawasih $\mathrm{R}$, Adenan M, Yudomustopo H, Tan MG. The attitudes of health providers towards abortion in Indonesia. Reprod Health Matt. 1993;1(2):32-40.

27. Harries J, Lince N, Constant D, Hargey A, Grossman D. The challenges of offering public second trimester abortion services in South Africa: health care providers' perspectives. J Biosoc Sci. 2012;44(2):197-208.

28. Mayers PM, Parkes B, Green B, Turner J. Experiences of registered midwives assisting with termination of pregnancies at a tertiary level hospital. Health SA Gesondheid. 2005;10(1):15-25.

29. Paul M, Gemzell-Danielsson K, Kiggundu C, Namugenyi R, Klingberg-Allvin M. Barriers and facilitators in the provision of post-abortion care at district level in central Uganda - a qualitative study focusing on task sharing between physicians and midwives. BMC Health Serv Res. 2014;14:28.

30. Aniteye P, Mayhew S. Shaping legal abortion provision in Ghana: using policy theory to understand provider-related obstacles to policy implementation. Health Re Policy and Syst. 2013;11:1-14.

31. Gmeiner AC, Van Wyk S, Poggenpoel M, Myburgh CP. Support for nurses directly involved with women who chose to terminate a pregnancy. Curationis. 2000;23(1):70-8.

32. Abdi J, Gebremariam MB. Health providers' perception towards safe abortion service at selected health facilities in Addis Ababa. Afr J Reprod Health. 2011;15(1):31-6

33. Buga GA. Attitudes of medical students to induced abortion. East Afr Med J. 2002;79(5):259-62.

34. Etuk SJ. Ebong, Okonofua FE. Knowledge, attitude and practice of private medical practitioners in Calabar towards post-abortion care. Afr J Reprod Health. 2003;7(3):55-64

35. Gallo MF. An assessment of abortion services in public health facilities in Mozambique: women's and providers' perspectives. Reprod Health Matt. 2004;12(24 Suppl):218-26.

36. Harrison A, Montgomery ET, Lurie M, Wilkinson D. Barriers to implementing south Africa's termination of pregnancy Act in rural KwaZulu/natal. Health Policy Plan. 2000;15(4):424-31.

37. Kasule J, Mbizvo MT, Gupta V. Abortion: attitudes and perceptions of health professionals in Zimbabwe. Cent Afr J Med. 1999;45(9):239-44.

38. Kidula NA, Kamau RK, Ojwang SB, Mwathe EG. A survey of the knowledge, attitude and practice of induced abortion among nurses in Kisii district, Kenya. J Obstet Gynaecol East Cent Africa. 1992;10(10):10-2.

39. Mngadi PT, Faxelid E, Zwane IT, Hojer B, Ransjo-Arrvidson AB. Health providers' perceptions of adolescent sexual and reproductive health care in Swaziland. Int Nurs Rev. 2008;55(2):148-55.

40. Mokgethi NE, Ehlers VJ, van der Merwe MM. Professional nurses' attitudes towards providing termination of pregnancy services in a tertiary hospital in the North West province of South Africa. Curationis. 2006;29(1):32-9.

41. Morhe ES, Morhe RA, Danso KA. Attitudes of doctors toward establishing safe abortion units in Ghana. Int J Gynaecol Obstet. 2007;98(1):70-4.

42. Okonofua FE, Shittu SO, Oronsaye F, Ogunsakin D, Ogbomwan S, Zayyan M. Attitudes and practices of private medical providers towards family planning and abortion services in Nigeria. Acta Obstet Gynecol Scand. 2005;84(3):270-80

43. Omo-Aghoja LO, Hammed A, Okonofua FE, Okpani OA, Koroye OC, Ojobo S, et al. A survey of attitudes and practices of reproductive health and family planning services among private medical practitioners in four states of the Niger-Delta region of Nigeria. Qua Primary Care. 2011;19(5):325-34.
44. Onah HE, Ogbuokiri CM, Obi SN, Oguanuo TC. Knowledge, attitude and practice of private medical practitioners towards abortion and post abortion care in Enugu. South-eastern Nigeria J Obstet Gynaecol. 2009;29(5):415-8.

45. Phuapradit W, Sirivongs B, Chaturachinda K. Abortion: an attitude study of professional staff at Ramathibodi hospital. J Med Assoc Thai. 1986;69 (1):22-7.

46. Varakamin S, Devaphalin V, Narkavonkit T, Wright NH. Attitudes toward abortion in Thailand: a survey of senior medical students. Stud Fam Plann. 1977:8(11):288-93.

47. Voetagbe G, Yellu N, Mills J, Mitchell E, Adu-Amankwah A, Jehu-Appiah K, et al. Midwifery tutors' capacity and willingness to teach contraception, post-abortion care, and legal pregnancy termination in Ghana. Hum Resour Health. 2010:8:2

48. Warenius LU, Faxelid EA, Chishimba PN, Musandu JP, Ongány AA, Nissen EBM. Nurse-midwives' attitudes towards adolescent sexual and reproductive health needs in Kenya and Zambia. Reprod Health Matt. 2006;14(27):119-28.

49. Wheeler SB, Zullig LL, Reeve BB, Buga GA, Morroni C. Attitudes and intentions regarding abortion provision among medical school students in South Africa. Int Perspect Sex Reprod Health. 2012:38(3):154-63.

50. Tey NP, Yew SY, Low WY, Suút L, Renjhen P, Huang MS, et al. Medical students' attitudes toward abortion education: Malaysian perspective. PLoS One. 2012;7(12):e52116.

51. Payne CM, Debbink MP, Steele EA, Buck CT, Martin LA, Hassinger JA, et al. Why women are dying from unsafe abortion: narratives of Ghanaian abortion providers. Afr J Reprod Health. 2013;17(2):118-28.

52. Schwandt HM, Creanga AA, Adanu RM, Danso KA, Agbenyega T, Hindin MJ. Pathways to unsafe abortion in Ghana: the role of male partners, women and health care providers. Contraception. 2013;88(4):509-17.

53. Harries J, Stinson K, Orner P. Health care providers' attitudes towards termination of pregnancy: a qualitative study in South Africa. BMC Public Health. 2009;9:296

54. Klingberg-Allvin M, Nga NT, Ransjo-Arvidson AB, Johansson A. Perspectives of midwives and doctors on adolescent sexuality and abortion care in Vietnam. Scand J Public Health. 2006;34(4):414-21.

55. Klingberg-Allvin M, Van Tam V, Nga NT, Ransjo-Arvidson AB, Johansson A. Ethics of justice and ethics of care. Values and attitudes among midwifery students on adolescent sexuality and abortion in Vietnam and their implications for midwifery education: a survey by questionnaire and interview. Int J Nurs Stud. 2007:44(1):37-46.

56. Poggenpoel M, Myburgh CP, Gmeiner A. One voice regarding the legalisation of abortion. Nurses who experience discomfort. Curationis. 1998;21(3):2-7.

57. Potgieter C, Andrews G. South African nurses' accounts for choosing to be termination of pregnancy providers. Health SA Gesondheid. 2004;9(2):20-30.

58. Walker $\mathrm{L}$. The practice of primary health care: a case study. Soc Sci Med. 1995;40(6):815-24.

59. International Confederation of Midwives, Essential Competencies for Basic Midwifery Practice 2010 [http://www.internationalmidwives.org/assets/ uploads/documents/CoreDocuments/ICM\%20Essential\% 20Competencies\%20for\%20Basic\%20Midwifery\%20Practice\% 202010,20revised\%202013.pdf]

60. International Confederation of Midwives, Model Midwifery Curriculum Outlines [http://www.internationalmidwives.org/what-we-do/ educationcoredocuments/model-curriculum-outlines-for-professionalmidwifery-education/packet-1-2-3-4.html]

61. World Health Organization. WHO Recommendations: Optimizing Health Worker Roles to Improve Access to key Maternal and Newborn Health Interventions Through Task Shifting. Geneva, Switzerland: World Health Organization; 2012.

62. Warriner IK, Wang D, Huong NT, Thapa K, Tamang A, Shah I, et al. Can midlevel health-care providers administer early medical abortion as safely and effectively as doctors? A randomised controlled equivalence trial in Nepal. Lancet. 2011;377(9772):1155-61.

63. Warriner IK, Merik O, Hoffman M, Morroni C, Harries J, My Huong NT, et al, Rates of complication in first-trimester manual vacuum aspiration abortion done by doctors and mid-level providers in South Africa and Vietnam: a randomised controlled equivalence trial. Lancet. 2006;368(9551):1965-72.

64. Rasch V. Unsafe abortion and postabortion care - an overview. Acta Obstet Gynecol Scand. 2011;90(7):692-700. 
65. Curtis C. Meeting health care needs of women experiencing complications of miscarriage and unsafe abortion: USAID's postabortion care program. J Midwifery Women's Health. 2007;52(4):368-75.

66. Trueman KA, Magwentshu M. Abortion in a progressive legal environment: the need for vigilance in protecting and promoting access to safe abortion services in South Africa. Am J Public Health. 2013;103(3):397-9.

67. Fiala C, Arthur JH. 'Dishonourable disobedience" - Why refusal to treat in reproductive healthcare is not conscientious objection. Woman Psychosomatic Gynaecol Obstetrics. 2014;1:12-23.

68. Sundaram A, Jlades N. The impact of Ghana's R3M programme on the provision of safe abortions and postabortion care. Health Policy and Planning. 2014. p. czu105v1-czu105.

69. Smit I, Bitzer EM, Boshoff EL, Steyn DW. Abortion care training framework for nurses within the context of higher education in the Western Cape. Curationis. 2009;32(3):38-46.

70. Turner K, Hyman AG, Gabriel MC. Clarifying values and transforming attitudes to improve access to second trimester abortion. Reprod Health Matt. 2008;16(31 Suppl):108-16.

71. Mitchell EM, Trueman K, Gabriel M, Bock LB. Building alliances from ambivalence: evaluation of abortion values clarification workshops with stakeholders in South Africa. Afr J Reprod Health. 2005;9(3):89-99.

\section{Submit your next manuscript to BioMed Central and take full advantage of:}

- Convenient online submission

- Thorough peer review

- No space constraints or color figure charges

- Immediate publication on acceptance

- Inclusion in PubMed, CAS, Scopus and Google Scholar

- Research which is freely available for redistribution 